\title{
COMMISSION 37: STAR CLUSTERS AND ASSOCIATIONS (AMAS STELLAIRES ET ASSOCIATIONS)
}

\author{
Report of Meetings, 21, 24, 27 and 29 August 1973
}

President: G. Larsson-Leander.

SECRETARY: R. Wielen.

\section{A. Administrative Session}

The first meeting of the Commission, on August 21, was devoted to administrative matters. The following items of the agenda were discussed:

(1) The Commission Report. The Report for the past triennium was prepared in due time and submitted to the General Secretary for printing. In order to give the Commission members opportunity to read the Report before publication, and thus possibility to suggest minor changes and corrections, the type-script had been mimeographed and copies distributed to the Commission members and to all other colleagues who had forwarded progress reports to the President. This procedure was much appreciated by the Commission, and the Report in its present form, as a critical review, was considered very useful. The Commission especially stressed the value of the extensive tabulations of current work, which have been a regular feature of the Commission 37 Reports. The Commission was strongly in favour of having all Reports of the various Commissions published in book form, as has been done up to now, and the President was urged to act accordingly when discussing the question with the General Secretary.

(2) Election of Commission officers. Proposals for new officers had been made in a circular letter issued by the President, after consulting the Organizing Committee. The proposed names were approved by the Commission. The President expressed his thanks to the colleagues now leaving the Organizing Committee.

(3) New Commission members. Sixteen colleagues had been proposed to, or had applied for membership in the Commission. Most of these names had been considered and approved by the Organizing Committee and almost all had been announced by the President in a previous circular letter. The Commission approved of all the candidates proposed as new members.

(4) Commission rules. The Commission opposed to the idea of establishing strict rules, but agreed that certain guide lines might be useful. It was decided that the length of service in the Organizing Committee should in general be limited to three periods (of three years each), exceptions being made, if necessary, for those elected as Presidents and Vice-Presidents. For the sake of continuity, a past President should remain within the Organizing Committee also during the subsequent threeyear period. Further, it was emphasized that proposals for new members of the Commission should be decided upon by the Commission itself.

(5) Atlas of globular clusters. The President announced that $\mathrm{Dr}$ G. Alcaino is preparing an atlas of galactic globular clusters, giving identification charts, stellar magnitudes, and other cluster data.

(6) Priorities in research. The question of assigning research priorities within the fields of the various Commissions had been raised by the General Secretary at a meeting with Commission Presidents. The matter was discussed by the Commission, and a number of important research topics were suggested and listed on the blackboard. It was found impossible, however, to assign priorities to the various topics. On the proposal of the President he was given the task to arrange the material and to prepare a draft to be distributed for the consideration of Commission members and other interested colleagues present in Sydney. The suggested additions and improvements to the draft were taken into account for the final version, given at the end of this Report.

(7) Circular letter from the Moscow Variable Star Bureau. The contents of the circular letter were discussed, but as the letter mainly concerned the field of Commission 27 no formal action was taken.

There being no further business items the meeting was adjourned. 


\section{B. Scientific Sessions}

The meeting on August 24 was mainly devoted to the topic of Stellar Rings. After an extensive introductory review, 'The Stellar Rings', given by J. Isserstedt, two critical papers were read in abstract form:

N. V. Vidal and K. $\AA$. Bern: Stellar Rings and the Structure of the Galaxy (presented by Bern), T. A. Uranova: To the Problem of the Stellar Rings (read by the President).

A large number of people participated in the ensuing general discussion.

After this the following two papers were presented:

F. J. Kerr: Neutral Hydrogen Observations of Globular Clusters,

G. Alcaino: An Atlas of Galactic Globular Clusters.

In connection with his paper Dr Alcaino exhibited for inspection pre-print copies of the Atlas.

The meeting on August 27 was a joint meeting with Commissions 25, 27, 34 and 40, on 'Galactic

Infrared and Microwave Sources'. The full report is given by Commisison 27.

The August 29 meeting, on 'Stellar Content of Associations and Clusters', was held jointly with Commission 45 . The full report of the meeting is given by Commission 45 .

\section{Importance of Research on Star Clusters and Associations}

Besides being of great interest per se, as stellar systems of various size, the clusters and associations are of great importance for many branches of astronomy and astrophysics. They provide information on star formation and stellar evolution, and they constitute almost ideal objects for testing theories in these fields. The correlation between the ages, abundances, and kinematics of clusters provides an essential clue to the early evolution of our Galaxy, and in the giobular clusters we have the oldest known objects in the Universe. Further, the clusters and associations are especially useful for cailibration of various astrophysical relationships, needed as fundamental data both in theoretical studies of stellar structure and in galactic research.

If the clusters and associations are to meet these expectations and demands, all kind of such objects have to be studied intensively, in order to segregate physical members from field stars. All possible methods should be used, but of particular value are spectral classifications, radial-velocity measurements, and proper-motion studies. To further the solution of the calibration problem, a list of especially useful objects might be prepared. Special regard has to be given to the chemical abundances, frequency of binaries, and the stellar-rotation velocities. Intermediate-band photometry and spectral studies of individual stars are needed. The faint ends of nearby clusters should be investigated more closely.

Extremely young clusters and other very young aggregates should be studied, because of their importance for the theories of star formation and the early stellar evolution. Similarly, the stars above the horizontal branch in globular clusters are of special interest for the late evolution.

A satisfactory classification scheme for globular clusters is needed, as well as mass and distance determinations for such clusters, using various methods.

The kinematical ages of associations should be more thoroughly investigated, and the reality of moving stellar groups should be checked. In the field of cluster dynamics much work remains to be done; thus, for instance, the time scale of dynamic evolution is rather uncertain.

The above is a summary of a discussion at the Commission 37 meeting on August 21, 1973. Many more important research items could be added. The Commission finds it impossible to assign priorities by number to the various problems outlined, as they are all of great importance and cover different areas of a large field. The question of priority must be decided upon by the individual researcher himself. 